\title{
Spatial Variation in Personal Exposure of Parking Attendants to Traffic Emissions in an Urban Conurbation
}

\author{
A. Tiwary ${ }^{*}$, A. Namdeo and A. Pareira \\ Civil Engineering \& Geosciences, Newcastle University, Newcastle, NE1 7RU, UK
}

\begin{abstract}
This study presents temporal and spatial variations in personal exposure of parking attendants in a busy conurbation in the northern part of the UK. Two traffic related pollutants - carbon monoxide (CO) and ultrafine particulates (UFP), mainly associated with urban drives, have been considered for two distinct locations- one, in the city centre and the other in a suburban area of Leeds, a prominent city in West Yorkshire. The monitoring of pollutants was conducted while parking attendants carried out their duty along the streets during different times of the year to capture the seasonal fluctuations.

Our results show a wide variation in exposure levels for both $\mathrm{CO}$ and UFP, marked both by seasonal and daily characteristics. There seems to be considerable variations in exposure levels depending on the location of the parking attendants with respect to traffic activity. Specifically, the level of exposure closer to market areas within the city centre, despite located in open spaces but closer to congested streets were found to be much higher owing to frequent stopping, stopping and idling of cars in search of parking spaces. This demonstrates the merit in setting up transport interchanges and park-and-ride schemes away from busy streets to ameliorate the exposure levels.
\end{abstract}

Keywords: CO, monitoring, personal exposure, pedestrian, traffic, UFP.

\section{INTRODUCTION}

The effects of transport-related air pollution on pedestrian's health have increased substantially in recent years [1]. This is of alarming concern to the growing number of non-motorised commuters alongside busy car traffic on inner-city roads. Recent studies suggest particulate matter exposure for pedestrians in Leicester, UK to be up to $50 \%$ higher than in cars [2]; large variability in peak exposures in London from turbulent flows [3] and the concentrations to be higher at traffic lights and near the pavement edge than in the centre of the pavement [4]. On the other hand, the use of onstreet car parking system has been reported to ameliorate pedestrian exposure, typically for parking attendants during their routine patrols on such streets $[5,6]$. These findings illustrate the importance of understanding the street-level traffic activities and the state of the vehicle (whether parked, idling or accelerating) on the pedestrian exposure levels.

Emissions from vehicles affect the quality of the air we breathe and have the most impact close to where traffic is greatest, i.e., in the centres of towns and cities and near busy roads. Field experiments, conducted in central London, as part of the Dispersion of Air Pollution and Penetration into the Local Environment (DAPPLE) project (www.dapple. org.uk) have shown $\mathrm{PM}_{2.5}$ and $\mathrm{CO}$ personal exposure measurements to be much higher than those recorded at a road side fixed monitoring station. This has been associated with peak exposure events, i.e. coincidences of high concentration and presence of a person [3,7]. It is the outdoor urban workers such as parking wardens that are

*Address correspondence to this author at the Civil Engineering \& Geosciences, Newcastle University, Newcastle, NE1 7RU, UK; Tel: 0044 191 2223682; E-mail: abhishek.tiwary@ncl.ac.uk more likely to be susceptible to such peak exposures because they spend most of their working time on streets closer to traffic. Hence they are deemed to be more vulnerable to health consequences from traffic pollutants. It is known that the highest $\mathrm{CO}$ exposures are directly associated with the amount of time spent working or commuting among very heavy traffic [8]. Therefore the exposure of individuals to an air pollutant is dependent on their daily activity and the location and time spent on these activities. In general, the population that is most likely to be exposed to air pollutants higher than average is the outdoor urban workers such as traffic police, parking wardens, street sweepers or newspaper vendors [9]. Pedestrians and outdoor workers are likely to be subjected to higher pollutant levels owing to their elongated ambient exposure. However, despite shorter journey times cyclists are reported to have substantially enhanced exposure levels to traffic emissions owing to increased respiratory activities [10].

This paper investigates the temporal and spatial variations of personal exposure of parking attendants to two pollutants related to traffic with known health effects carbon monoxide $(\mathrm{CO})$ and ultrafine $(<100 \mathrm{~nm})$ particles (UFP). The rationale for choosing parking attendants as the target group in this study is owing to their large amount of time spent along roads, compared to the majority of people in the UK spending on average only $17 \mathrm{~min}$ a day either walking or jogging along the roads [11]. The main purpose of this exercise has been to develop an understanding through primary data gathering on the role of street characteristics and traffic activities on the overall exposure levels of parking attendants. 


\section{MATERIALS AND METHODS}

\subsection{Study Site Description}

The study site is located in the metropolitan area of Leeds, comprising of three different locations (Fig. 1) - two in the Leeds city centre (Park Row and Market Area) and one in a suburban area (Headingley). Leeds is a large conurbation in the West Yorkshire County in the North of England, with an estimated flow of around 35,000 vehicles to the City centre during the peak hours, comprising mainly of cars (over 55\%) and buses (over 22\%) [12]. In order to cover a wide range of exposure levels specific attention was given during site selection as to choose different routes. These were based on an established approach from the literature [13] in order to provide representative personal monitoring, typically characterised by contrasting traffic conditions. Nevertheless, this selection process was restricted by the availability of sites where parking attendants normally perform their duties. Park Row area (bottom left patch on the map) is characterised by several storey buildings on either side, predominantly businesses such as banks, financial companies, and restaurants. On the other hand, Market Area (bottom right patch on the map) is mainly commercial in nature and is characterised by a busy bus corridor with several storey buildings on both sides, Leeds Market Car Park is located at the centre of this area and Leeds Coach/Bus Station is located to the southeast of the area. Headingley suburban area (top patch on the map) is approximately $3 \mathrm{~km}$ North West of Leeds City Centre. The A660, a main radial route into the city, is a very busy bus corridor and runs to the east of this area. Headingley area has a varied environment, with a residential area in its centre and the presence of the Leeds Metropolitan University Campus next to it, generating high traffic volumes throughout the terms. Traffic data for the analysis was obtained from Leeds City Council for East Parade, Headrow and Otley Road.

\subsection{Monitoring}

High resolution real time measurements (10 seconds average) were taken in the three locations during the winter and the summer in 2007. A pilot survey was carried out in November 2006 to test the practicality of the data collection method. Measurements of CO and UFP were respectively taken using $\mathrm{T} 15 \mathrm{v}$ Langan $\mathrm{CO}$ measurer and TSI Condensation Particle Counter Model 3007. These portable monitors were carried by parking attendants during their beats. Portable global positioning system (GPS) devices (Garmin ${ }^{R}$ eTrexLegend) were carried by the parking attendants to locate their position and later match with corresponding $\mathrm{CO}$ and UFP measurements. The first set of $\mathrm{CO}$ measurements carried out by the parking attendants was undertaken for three days including a Saturday during winter in February 2007. Summer surveys were carried out in July 2007 also for three days including a Saturday. Data was collected from the start of the parking attendants work shift between $0700 \mathrm{~h}$ and $0800 \mathrm{~h}$ and ended at the end between $1600 \mathrm{~h}$ and $1800 \mathrm{~h}$. Particulates data collection was also carried out during winter in February 2007 and during summer in July and August 2007. For the accuracy of the measurements, zero and span tests were carried out before each set of surveys with all CO and UFP monitors used for the study. A total of 24 usable sample sets, comprising of measurements at 10 -second resolution, were available for analysis. These consisted of eight $\mathrm{CO}$ samples collected during the winter, nine $\mathrm{CO}$ samples collected during the summer, three particles samples collected during winter, and four particles samples collected during the summer.

\section{RESULTS AND DISCUSSIONS}

\subsection{CO Exposure Levels}

Average $\mathrm{CO}$ exposure levels in three areas are shown in Table 1 . The $\mathrm{CO}$ daily mean concentrations were well below

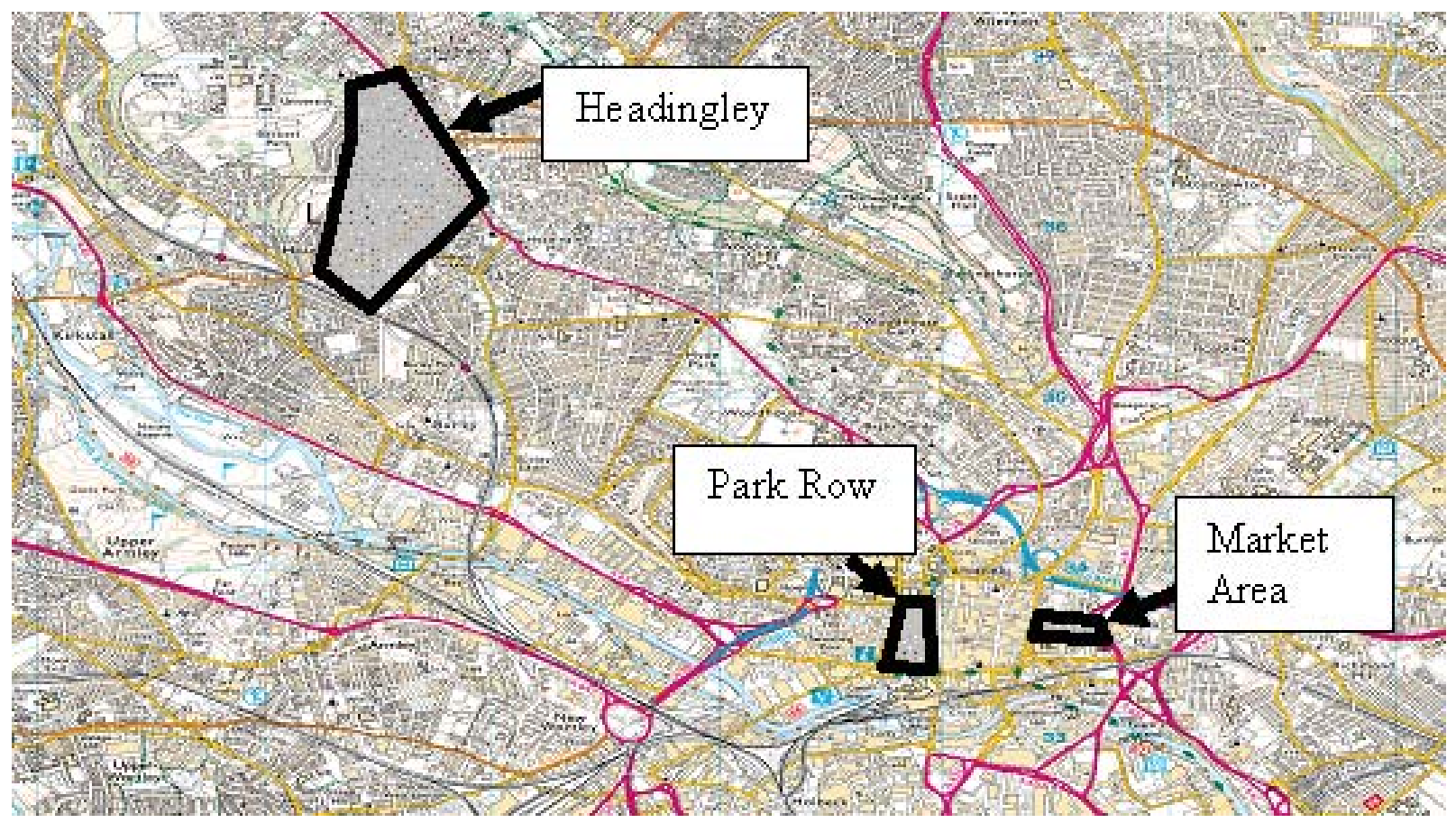

Fig. (1). Study area location plan showing the three different monitoring sites (Crown Copyright Ordnance Survey Map. An Edina/JISC supplied service). 
Table 1. CO Exposure Levels in Three Areas

\begin{tabular}{|c|c|c|c|c|c|c|c|}
\hline \multirow{3}{*}{\multicolumn{2}{|c|}{ Sampling Area and Day }} & \multicolumn{6}{|c|}{ CO Exposure Levels (ppm) } \\
\hline & & \multicolumn{3}{|c|}{ Summer 2007} & \multicolumn{3}{|c|}{ Winter 2007} \\
\hline & & Mean & Maximum & Standard Deviation & Mean & Maximum & Standard Deviation \\
\hline \multirow{2}{*}{ Area 1 - Park Row } & Weekday & 1.388 & 5.330 & 0.820 & 1.178 & 4.155 & 0.378 \\
\hline & Saturday & 0.888 & 3.421 & 0.433 & 0.428 & 4.406 & 0.482 \\
\hline \multirow{2}{*}{ Area 2 - Market Area } & Weekday & 1.204 & 5.860 & 0.708 & 0.270 & 3.008 & 0.332 \\
\hline & Saturday & 0.767 & 1.902 & 0.241 & - & - & - \\
\hline \multirow{2}{*}{ Area 3- Headingley } & Weekday & 1.782 & 9.255 & 1.483 & 0.380 & 4.091 & 0.543 \\
\hline & Saturday & 2.196 & 4.922 & 0.414 & 0.314 & 4.532 & 0.436 \\
\hline
\end{tabular}

the UK National Air Quality Objective of 8ppm. However, there is a wide variation in exposure levels between the seasons and weekdays. Summer levels are higher than winter levels in Market Area and Headingley whereas this variation is small in Park Row. The winter observations showed large fluctuations and particularly in the case of Headingley site the maximum recorded values for both the weekdays and the weekends were much higher compared to the sample mean. Hence, the standard deviations for these observations exceeded the corresponding mean values.

As expected weekday levels are higher than weekend levels indicating the influence of traffic activity. Figs. $(\mathbf{2}, \mathbf{3})$ show spatial variation in personal exposure of parking attendants to CO. These figures clearly show that there is significant variation in exposure levels depending on the location of parking attendants with respect to traffic activity. If the attendants were near busy roads (e.g. Otley Road in Headingley) or in street canyons (Park Row) then they are exposed to higher CO levels compared to the locations which are not near busy traffic (e.g. side streets).

Market Area presents an interesting story; here parking attendants' beats are near shops and in an open car park area where due to frequent stopping, stopping and idling of cars in search of parking spaces has created some hot-spots as shown in Fig. (3).
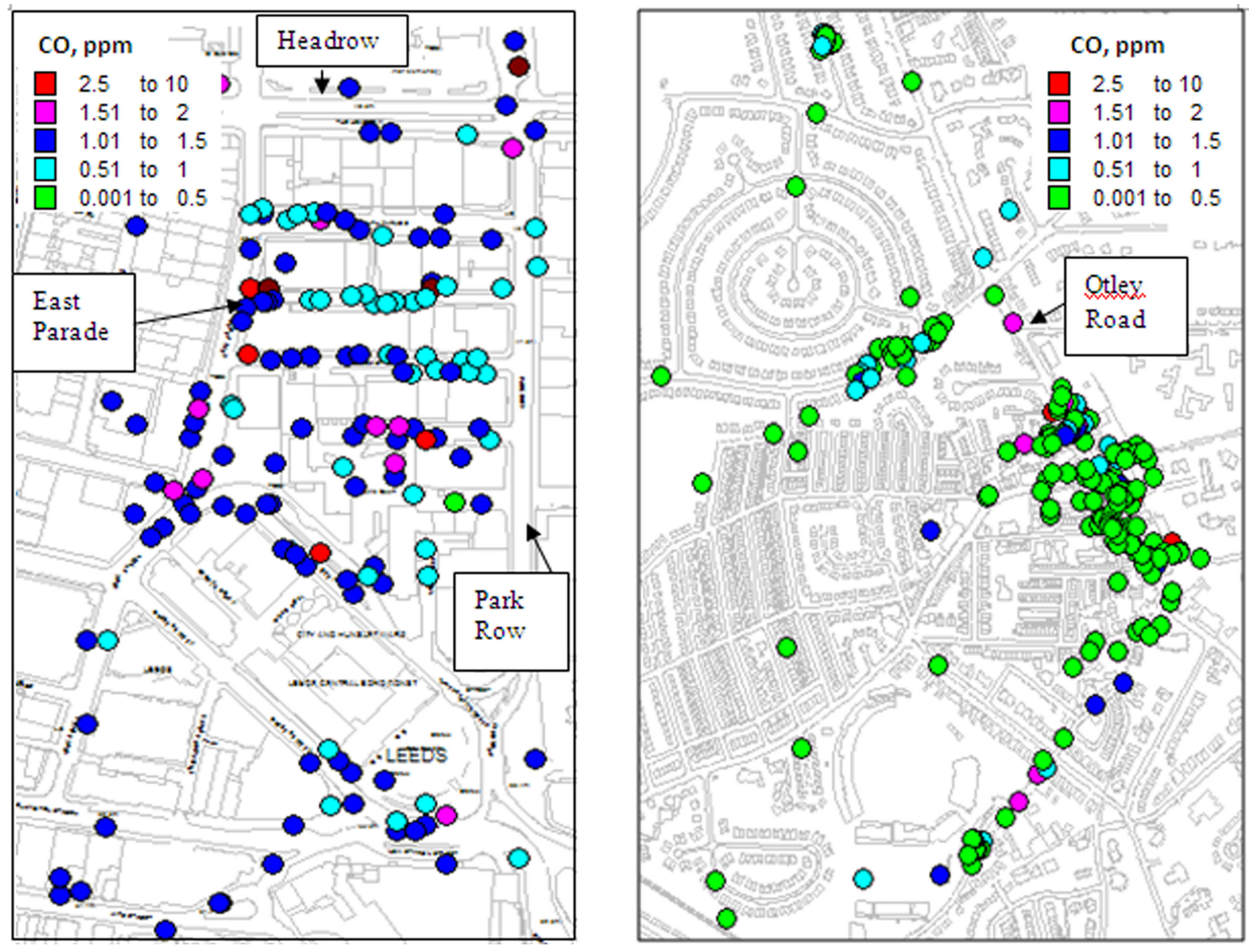

Fig. (2). Spatial variation in CO exposure levels in Park Row (left panel); Headingley (right panel) (Crown Copyright Ordnance Survey Map. An Edina/JISC supplied service). 


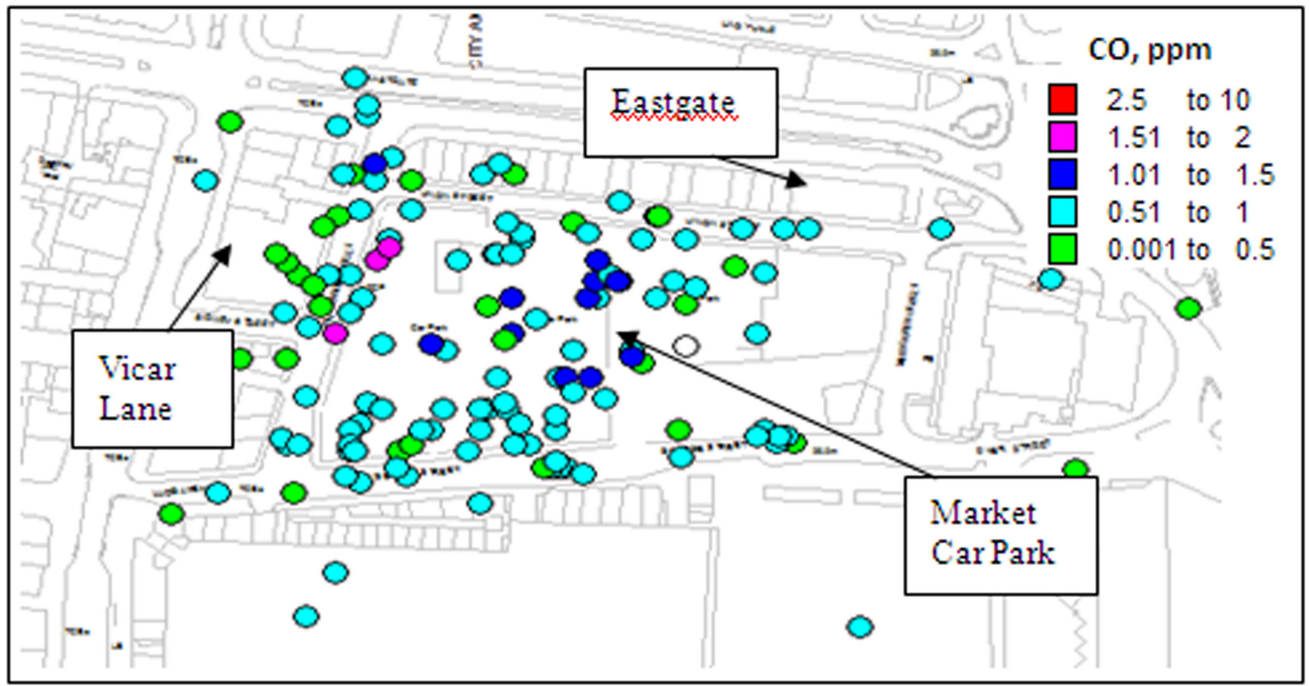

Fig. (3). Spatial Variation in CO Exposure Levels in Market Area (Crown Copyright Ordnance Survey Map. An Edina/JISC supplied service).

\subsection{Ultrafine Particles Exposure Levels}

Ultrafine particles (UFP) are measured as number of particles per $\mathrm{cm}^{3}$ volume of air. Currently there are no standards set for UFPs, however, an expert elicitation on the human health effects of ambient UFP exposure [14] suggested medium to high likelihood of cardiovascular and respiratory diseases, lung function decrements and mortality, specially associated with transport-related emissions. This is owing to their high alveolar deposition fraction and large surface area resulting in potentially higher toxicity $[14,15]$. Contrasting to $\mathrm{CO}$ exposure levels, UFP levels are higher in winter than in summer by a factor of 2 to 3 (Table 2). UFP exposure levels are generally higher during AM peak hours compared to PM peak hours. These observations are in agreement with some recent studies also reporting more frequent UFP spikes in the morning compared to later part of the day $[16,17]$, attributable mainly to a combination of two factors - one, increased number of diesel and high particle emitting vehicles in the morning rush hour; two, increased condensation of organic vapours and slower rates of conversion to larger particles for the cooler, stable air conditions during early morning hours. Figs. $(\mathbf{4}, \mathbf{5})$ show spatial variation in personal exposure of parking attendants to UFP.
UFP concentrations were highest in Park Row followed by Market Area and Headingley. The effect of traffic activity is clearly evident from Fig. (4) where parking attendants are exposed to an order of magnitude higher UFP levels near busy roads (e.g. Otley Road) compared to the residential area. The same observation was made in Market Area.

\section{CONCLUSIONS}

Parking attendants are exposed to varying levels of pollutants in their beat. This depends on several factors, including the location of the road with respect to the surrounding built-up area, the meteorological and seasonal influences on the dispersion of traffic-generated emissions and the on-street parking and stop-start traffic activities on the roads. There seems to be a considerable disparity in the exposure levels for CO and UFP depending on the location of the parking attendants with respect to traffic activity. For instance, despite located in open spaces, their exposure levels closer to market areas within the city centre were found to be much higher owing to frequent congestions, stopping and idling of cars in search of parking spaces. This can be alleviated through adequate planning instruments to tackle the road emissions through park-and-ride or interchange schemes. This study was primarily aimed to collect representative samples from distinct road locations.

Table 2. Ultrafine Particles Exposure Levels in Three Areas

\begin{tabular}{|c|c|c|c|c|c|c|c|}
\hline \multirow{2}{*}{\multicolumn{2}{|c|}{ Sampling Area and Time }} & \multicolumn{6}{|c|}{ Ultrafine Particles Exposure Levels (Particles $\mathbf{c m}^{-3}$ ) } \\
\hline & & Mean & Maximum & Standard Deviation & Mean & Maximum & Standard Deviation \\
\hline \multirow{2}{*}{ Area 1 (Park Row) } & $\mathrm{AM}$ & 42,203 & 371,084 & 29,724 & 104,413 & 308,414 & 40,993 \\
\hline & $\mathrm{PM}$ & 32,955 & 192,924 & 20,619 & 82,033 & 361,234 & 48,155 \\
\hline Area 2 (Market Area) & PM & 39,842 & 126,777 & 18,208 & 67,861 & 226,189 & 27,936 \\
\hline \multirow{2}{*}{ Area 3 (Headingley) } & $\mathrm{AM}$ & 32,127 & 206,011 & 26,748 & 74,615 & 234,871 & 41,450 \\
\hline & $\mathrm{PM}$ & 31,885 & 221,301 & 23,594 & 26,193 & 201,140 & 25,639 \\
\hline
\end{tabular}



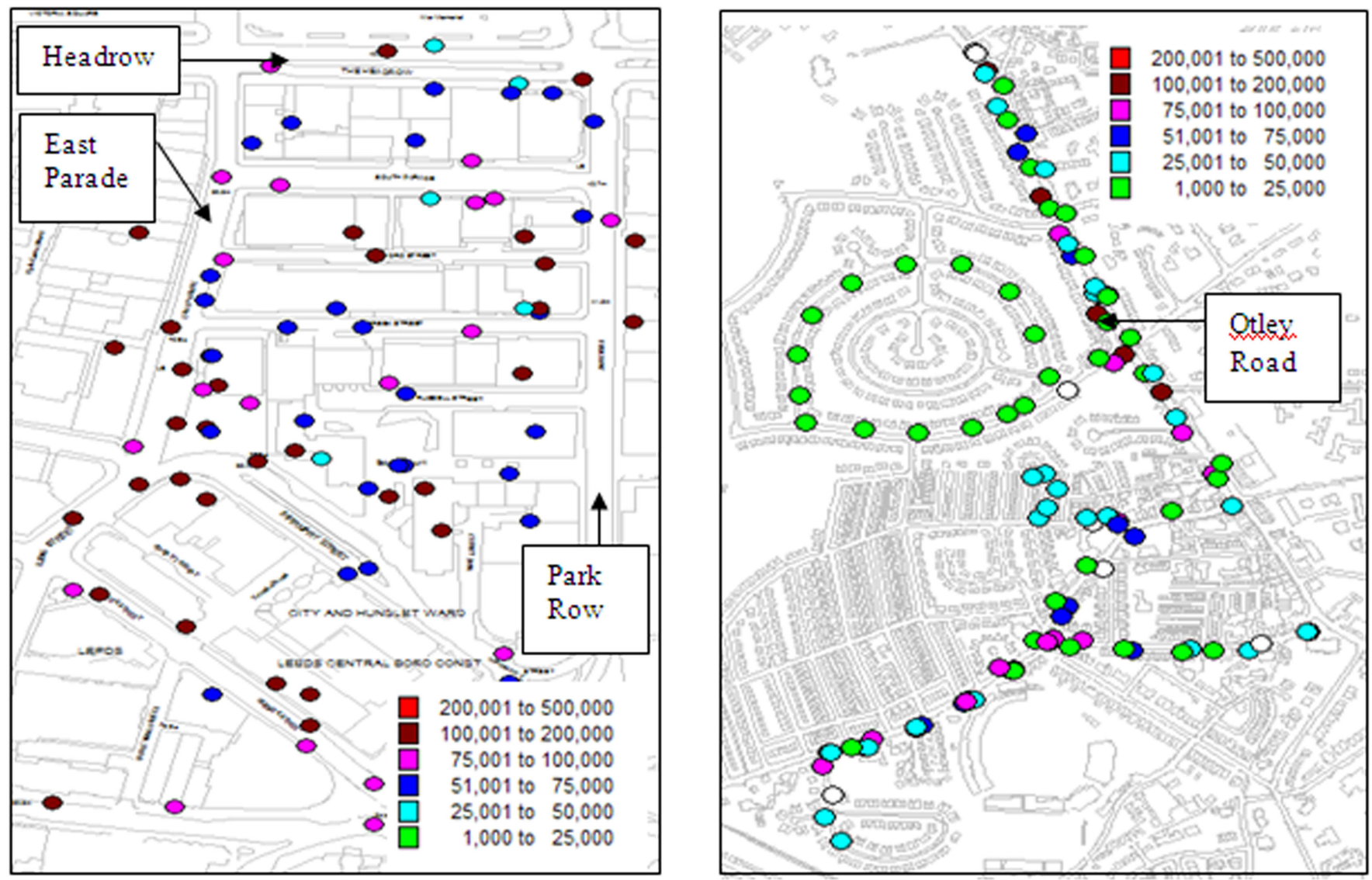

Fig. (4). Spatial Variation in UFP (particles $\mathrm{cm}^{-3}$ ) Exposure Levels in Park Row (left panel); Headingley (right panel) (Crown Copyright Ordnance Survey Map. An Edina/JISC supplied service).

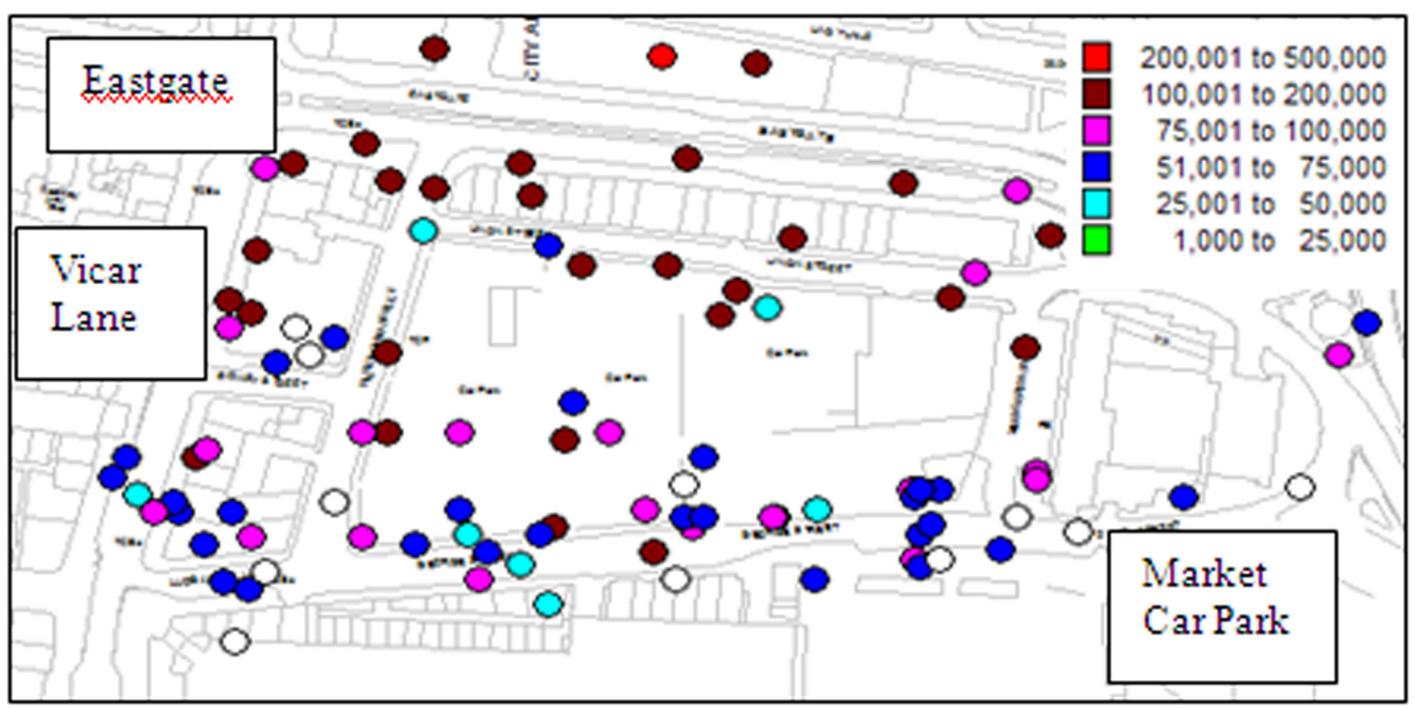

Fig. (5). Spatial Variation in UFP Exposure Levels in Market Area (Crown Copyright Ordnance Survey Map. An Edina/JISC supplied service).

However, it was limited in its scope by the availability of information on the routes where parking attendants operate as well as their willingness to participate in this voluntarily. Therefore, extending this approach to a full-scale study in the future would facilitate in improved understanding of the exposure levels of pedestrians who may be subjected to chronic levels of traffic-borne pollutants.

\section{ACKNOWLEDGEMENT}

None declared.

\section{CONFLICT OF INTEREST}

None declared. 


\section{REFERENCES}

[1] Krzyzanowski M, Kuna-Dibbert B, Schneider J. Health effects of transport-related air pollution. World Health Organisation, Geneva 2005.

[2] Gulliver J, Briggs DJ. Journey-time exposure to particulate air pollution. Atmos Environ 2007; 41(34): 7195-207.

[3] Wang H, Colvile RN, Pain C, Aristodemou E, ApSimon HM. Understanding peak pedestrian exposures due to traffic emissions within the urban environment. Transp Res Part D 2011; 16: 392401.

[4] Kaur S, Nieuwenhuijsen MJ, Colvile RN. Pedestrian exposure to air pollution along a major road in central London, UK. Atmos Environ 2005; 39: 7307-20.

[5] Gallagher J, Gill LW, McNabola A. Optimising the use of on-street car parking system as a passive control of air pollution exposure in street canyons by large eddy simulations. Atmos Environ 2011; 45(9):1684-94.

[6] McNabola A, Broderick BM, Gill LW. A numerical investigation of the impacts of low boundary walls on pedestrian exposure to air pollutants in urban street canyons. Sci Total Environ 2009; 407: 760-9.

[7] Greaves SP, Hamers J. Variability of exposure to fine particulates while cycling. Proceeding of the 29th Australasian Transport Research Forum, Gold Coast 2006.
[8] Vellopoulou AV, Ashmore MR. Personal exposures to carbon monoxide in the city of Athens: I. Commuters' exposures. Environ Int 1998; 24 (7): 713-20.

[9] Violante FS, Barbieri A, Curti S, Sanguinetti G, Graziosi F. Urban atmospheric pollution: personal exposure versus fixed monitoring station measurements. Chemosphere Environ Int 2006; 64: 1722-9.

[10] Weichenthal S, Kulka R, Dubeau A, Martin C, Wang D, Dales R. Traffic-related air pollution and acute changes in heart rate variability and respiratory functions in urban cyclists. Environ Health Perspect 2011 doi: 10.1289/ehp.1003321.

[11] Lader D, Short S, Gershuny J. The time use survey 2005. Office for National Statistics, London 2006.

[12] LCC. Leeds traffic flow report. Leeds City Council 2009.

[13] Gulliver J, Briggs DJ. Personal exposure to particulate air pollution in transport microenvironments. Atmos Environ 2004; 38 (1): 1-8.

[14] Knol AB, de Hartog JJ, Boogaard H, et al. Expert elicitation on ultrafine particles: likelihood of health effects and causal pathways. Particle Fibre Toxicol 2009; 6: 19-35.

[15] Sabaliauskas K, Evans G. Exposure to ultrafine particles in urban centres. In: Zereini F, Wiseman CLS, Eds. Urban airborne particulate matter. Berlin, Heidelberg: Springer-Verlag 2010.

[16] Hu S, Fruin S, Kozawa K, Mara S, Paulson SE, Winer AM. A wide area of air pollutant impact downwind of a freeway during presunrise hours. Atmos Environ 2009; 43: 2541-9.

[17] Kozawa KH, Fruin SA, Winer AM. Near-road air pollution impacts of goods movement in communities adjacent to the ports of Los Angeles and long beach. Atmos Environ 2009; 43: 2960-70.

(C) Tiwary et al:; Licensee Bentham Open.

This is an open access article licensed under the terms of the Creative Commons Attribution Non-Commercial License (http: //creativecommons.org/licenses/by$\mathrm{nc} / 3.0 /$ ) which permits unrestricted, non-commercial use, distribution and reproduction in any medium, provided the work is properly cited. 